\title{
THE ALDOSTERONE BLOCKING EFFECTS OF SPIROLACTONES
}

\author{
VICTOR A. DRILL, PH.D., M.D.* \\ Received for publication October 2, 1961
}

The possibility that a salt regulating hormone played a causative role in the production of edema was developed from the early reports of several investigators. Various authors were able to obtain urinary extracts with good sodium retaining effects from edematous patients with congestive heart failure, nephrosis, or cirrhosis of the liver ( $c f$. 1-4). Simpson, Tait, and Bush (5) discovered the steroid aldosterone in 1952, and in 1954 the sodium retaining factor in the urinc of edematous patients was identified as aldosterone by Luetscher and coworkers $(6,7)$.

In view of the probable role that aldosteronc played in the production and maintenance of edema we then asked the question "Would compounds with an aldosterone-blocking activity be effective in relieving edema?". There was an excellent chance that such a relationship would exist and experiments were begun in 1954 by Dr. C. M. Kagawa to study the effects of salt retaining steroids so as to reliably determine their effect on electrolyte excretion in experimental animals. These investigations were followed by an evaluation of structurally related steroids to determine whether or not they would block the electrolyte effects of the mineralocorticoids. Such studies led to the development of new steroids, the spirolactones, which are capable of blocking the salt retaining effects of desoxycorticosterone and aldosterone in laboratory animals and of producing a diuresis in patients with edema. The properties of the spirolactones, particularly Aldactone, will be discussed.

\section{STRUGTURE AND EFFECTIVENESS}

The spirolactones are a group of steroids that have the structure shown in Figure 1. SC-5233, the first compound with activity in this series, was effective only when administered parenterally to experimental animals $(8,9)$. It was, however, effective in large doses parentcrally in patients (10). SC-8109, the next derivative developed, was effective orally but the dosages required in patients ( 1 or 2 grams per day) were too large to be practical. The third compound, SC-9420, now called spironolactone or Aldactone**, was about five times as effective orally in the rat as SC-8109; clinically the increase in activity has been about $2 \frac{1}{2}$ fold.

\footnotetext{
* Director of Biological Research, G. D. Searle \& Co., Chicago, Illinois, U.S.A. ; Professorial Lecturer in Pharmacology, University of Illinois College of Medicine; Lecturer in Pharmacology, Northwestern University Medical School.

** 3-(3-Oxo-7/-acetylthio-17-hydroxy-4-androsten-17 $x$-yl) propionic acid $\gamma$ lactone.
} 
Kagawa has reported on the biological properties of these steroids (11-14) and summaries of various clinical studies are available (15-17). Inasmuch as Aldactone is now the steroid employed clinically, the present paper will be concerned almost entirely with the properties and usefulness of this compound.

\section{PHARMAGOLOGICAL PROPERTIES OF ALDACTONE}

The ability of various steroids to block the electrolyte effects of desoxycorticosterone and aldosterone was evaluated in adrenalectomized rats as described by Kagawa (8). In initial studies, because of scarcity of aldosterone, rats were injected with desoxycorticosterone acetate (DCA) to produce sodium retention and potassium excretion. Compounds which were active against DCA were then studied for their effects against the sodium retention and potassium excretion induced by aldosterone.

\section{A. Renal Effects}

Mineralocorticoid blocking effects. DCA administration causes sodium retention and potassium excretion, as determined by urinary values in the rat (Table 1). The ratio of $\mathrm{Na}: \mathrm{K}$ in the urine is therefore markedly decreased, and this ratio serves as a means of estimating the blocking effect of steroids. Aldactone blocks the action of DCA, returning the excre-

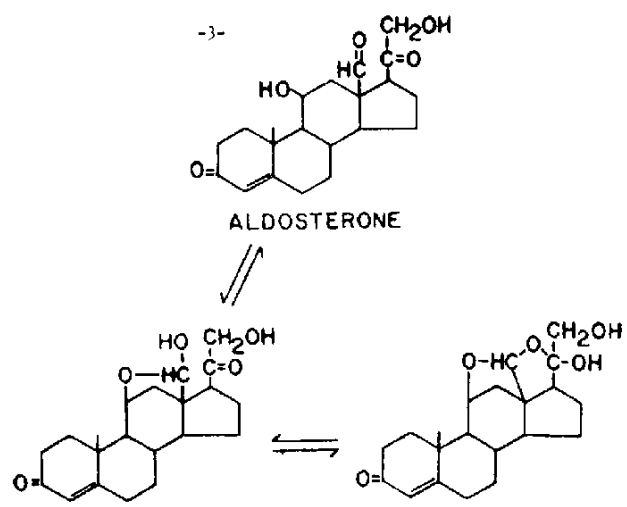

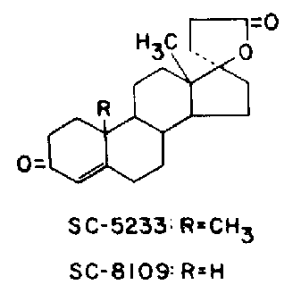

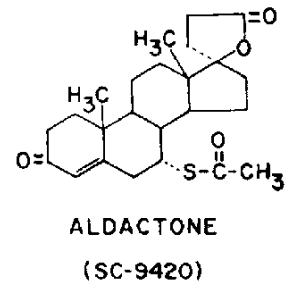

Fig. 1. Structure of aldosterone and 17-spirolactones.

TABLE 1. Blocking action of Aldactone on urinary electrolyte cffects of DCA in adrenalectomized rats.

\begin{tabular}{ccccc}
\hline $\begin{array}{l}\text { DCA } \\
(\mu \mathrm{g})\end{array}$ & $\begin{array}{c}\text { Aldactone } \\
(\mathrm{mg})\end{array}$ & \multicolumn{3}{c}{ Mean Log Valucs } \\
\cline { 4 - 6 } & & $\mathrm{Na}$ & $\mathrm{K}$ & $(\mathrm{Na} \times 10) / \mathrm{K}$ \\
\hline- & - & 0.78 & 0.45 & 1.34 \\
12 & - & 0.36 & 0.62 & 0.77 \\
12 & 0.1 & $0.46^{*}$ & $0.56^{*}$ & $0.91^{*}$ \\
12 & 1.6 & $0.77^{*}$ & $0.57^{*}$ & $1.20^{*}$ \\
12 & 4.8 & $0.80^{*}$ & 0.63 & $1.17^{*}$ \\
\hline
\end{tabular}

* $\mathrm{P}<0.05$ relative to $\mathrm{DGA}$ tion pattern of sodium, potassium, and $\mathrm{Na}: \mathrm{K}$ ratio towards normal (12). It will be noted in Table 1 that the effect reaches a maximum and is not further increased by the highest dose of Aldactone.

Aldosterone and DCA produce similar changes in the electrolyte excretion pattern, although aldosterone is approximately 40 times as potent. Kagawa (12) then demonstrated that Aldactone can counteract the sodium retention and potassium excretion produced 
TABIE 2. Blocking action of Aldactone on urinary electrolyte effects of aldosterone in adrenalectomized rats.

\begin{tabular}{lcccccc}
\hline \multicolumn{2}{c}{ Treatment/Rat } & $\begin{array}{c}\text { Number } \\
\text { Animals }\end{array}$ & \multicolumn{3}{c}{ Mean Log Response } \\
Aldosterone & Aldactone & Na & $\mathrm{K}$ & $(\mathrm{Na} \times 10) / \mathrm{K}$ \\
\hline - & - & 96 & 1.14 & 0.83 & 1.34 \\
$0.9 \mu \mathrm{g}$ & - & 16 & 0.82 & 1.03 & 0.80 \\
$0.9 \mu \mathrm{g}$ & $0.2 \mathrm{mg}$ & 8 & 0.87 & 0.98 & 0.89 \\
$0.9 \mu \mathrm{g}$ & $0.4 \mathrm{mg}$ & 8 & $0.97^{*}$ & 0.95 & $1.02^{*}$ \\
$0.9 \mu \mathrm{g}$ & $0.8 \mathrm{mg}$ & 8 & $1.03^{*}$ & $0.92^{*}$ & $1.11^{*}$ \\
\hline
\end{tabular}

* $\mathbf{P}<0.05$ relative to aldosterone

TABLE 3. Blocking action of Aldiactone on urinary electrolyte effects of hydrocortisone in adrenalectomized rats.

\begin{tabular}{ccccc}
\hline $\begin{array}{c}\text { Hydro- } \\
\text { cortione } \\
(\mu \mathrm{g})\end{array}$ & $\begin{array}{c}\text { Aldactone } \\
(\mathrm{mg})\end{array}$ & \multicolumn{3}{c}{ Mean } \\
\cline { 5 - 6 } & & $\mathrm{Na}$ & $\mathrm{K}$ & $(\mathrm{Na} \times 10) / \mathrm{K}$ \\
\cline { 5 - 6 } 400 & - & 1.08 & 1.30 & 0.78 \\
400 & 0.2 & $1.24^{*}$ & 1.32 & $0.93^{*}$ \\
400 & 0.4 & $1.27^{*}$ & 1.22 & $1.05^{*}$ \\
400 & 0.8 & $1.37^{*}$ & 1.23 & $1.14^{*}$ \\
\hline
\end{tabular}

* $\mathrm{P}<0.05$ relative to hydrocortisone by aldosterone (Table 2).

The electrolyte effects of hydrocortisone can also be blocked (Table 3). In this instance reversal of the $\mathrm{Na}: \mathrm{K}$ response was obtained primarily from changes of sodium excretion (12).

The spirolactones do not change effective renal plasma flow in patients (18) and the glomerular filtration rate is either not influenced $(18,19)$ or may tend to fall slightly $(18,20)$. The urinary

excretion of $\mathrm{Na}^{+}, \mathrm{Cl}^{-}$, and water is increased whercas the excretion of $\mathrm{K}^{+}$(usually), ammonia, phosphate, and titratable acid is decreased in normal subjects and in patients with edema $(10,18,21-24)$. Liddle (22-25) has remarked that the spirolactones differ from most other diuretics in reducing rather than increasing potassium excretion, an effect which may be clinically desirable. The renal clearance of endogenous creatinine is not altered $(10,22,26)$ although it may decrease in certain patients with the nephrotic syndrome $(20)$.

\section{B. Competitive Blocking Effect of Spirolactones}

Initial observations indicated that the spirolactones may be acting as competitive blockers to the mineralocorticoids. To be considered as such the spirolactones must possess certain additional properties, as follows :

I. They should be inactive as sodium excreting substances when given alone to adrenalectomized rats.

2. They should be inactive as diuretics in intact animals not receiving a mincralocorticoid.

3. There should be a reversible inhibition of the blocking response produced by the spirolactones with increasing doses of mineralocorticoid.

The results obtained in such studies are described below. 
Effect in adrenalectomized rats. The lack of effect of Aldactone when given to adrenalectomized rats not treated with salt retaining steroids is illustrated in Table 4. It will be noted that even at high dose levels there is no significant effect on potassium excretion, sodium excretion or the sodium/ potassium ratio (4). Thus, in the absence of mineralocorticoids Aldactone is without effect on electrolyte excretion.

Effect in the intact dog and rat. Aldactone is not diuretic in normal dogs (Table 5). Such animals received a normal sodium intake and mineralocorticoids were not administered. Under the same circumstances small doses of $A^{1}$-cortisone or hydrochlorothiazide produce a significant effect on urine volume and sodium excretion.

Similar studies were performed in normal saline-loaded rats not injected with mineralocorticoids (14). Again, under these conditions $\Delta^{1}$-cortisone and hydrochlorothiazide were effective diuretics, whereas Aldactone was inactive cven at a high dose (Table 6).

Reversal of blocking effect of spirolactones. In a further series of studies Kagawa administered various dose combinations of SC-5233 and DCA. Although a given dose of SC-5233 blocked the salt retaining effects of DCA, this could be reversed by giving higher doses of DCA to the animals (Fig. 2). Further, if a high dose of DCA was given, a larger dose of SC5233 was required to reverse the sodium retaining effects. This again could be overcome by further incrcasing the
TABLE 4. Effect of Aldactone given alone in adrenalectomized rats.

\begin{tabular}{cccc}
\hline $\begin{array}{c}\text { Aldactone } \\
(\mathrm{mg})\end{array}$ & \multicolumn{3}{c}{ Mean Log Response } \\
\cline { 2 - 4 } & $\mathrm{Na}$ & $\mathrm{K}$ & $(\mathrm{Na} \times 10) / \mathrm{K}$ \\
\hline- & 1.37 & 0.86 & 1.51 \\
0.26 & 1.34 & $0.74^{*}$ & 1.59 \\
7.8 & 1.26 & 0.84 & 1.43 \\
\hline
\end{tabular}

* $\mathbf{P}<0.05$

TARI.E 5. Diuretic activity in normal dog.

\begin{tabular}{|c|c|c|c|}
\hline \multirow{2}{*}{ Gompound } & \multirow{2}{*}{ Route } & \multicolumn{2}{|c|}{ Effective Dose (mg) } \\
\hline & & Volume & $\mathrm{Na}$ \\
\hline$d^{1}$-Cortisone & subc. & 0.11 & 0.10 \\
\hline Hydrochlorothiazide & oral & 0.36 & 0.36 \\
\hline Aldactone & oral & $>18.0$ & $>18.0$ \\
\hline
\end{tabular}

TABLE 6. Diuretic activity in normal salineloaded rats.

\begin{tabular}{llrr}
\hline \multirow{1}{*}{ Compound } & Route & \multicolumn{2}{c}{ Effective Dose (mg) } \\
\cline { 2 - 3 } & & Volume & $\mathrm{Na}$ \\
\hline $4^{\text {-Cortisone }}$ & subc. & $\mathbf{0 . 3}$ & 0.2 \\
Hydrochlorothiazide & oral & 0.2 & 0.2 \\
Aldactonc & subc. & $>12.0$ & $>12.0$ \\
\hline
\end{tabular}

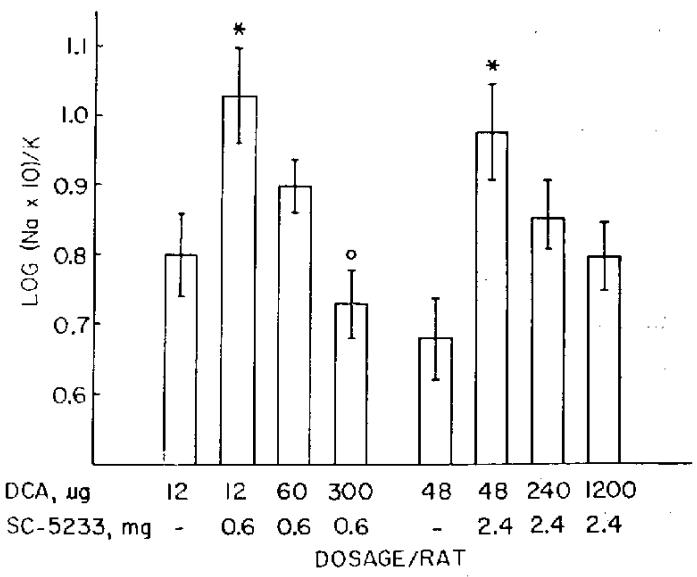

FIG. 2. Reversal of the blocking effects of SC-5233 by large excesscs of DGA in adrenalectomized rats. 
dose of the mineralocorticoid (11). These data demonstrate reversible inhibition of the blocking response and indicate that the inhibition is competitive in nature.

Blocking action in man. Based on the above series of experiments Kagawa and associates postulated that SC-5233, the first spirolactone to be studied, acted as a competitive inhibitor of aldosterone. This interpretation of mcchanism of action was supported by the studies of Liddle $(10,22,25)$. He noted that the drugs reverse the known actions of aldosterone on renal function on both dogs and man. He also observed that aldosterone production by the adrenal is not decreased, thus indicating that the spirolactones act peripherally at the renal level to block aldosterone rather than to inhibit its production. In many patients, on the contrary, the output of aldosterone was increased during treatment. Other data indicating a competitive blocking effect of the spirolactones in man has been summarized by Gantt (16).

Site of action of Aldactone. The aldosterone-blocking effect of Aldactone and the lack of non-specific diuretic activity, as demonstrated by the data in tables 2, 3, and 4 , indicate that Aldactone is acting in a manner different from that of the usual diuretics. It is known that aldosterone acts in the distal convoluted renal tubule to cause reabsorption of sodium and secretion of potassium and hydrogen $(22,27)$. It is probable, therefore, that the spirolactones exert their blocking effect in the distal portion of the renal tubules. Evidence for this site of action has been obtaincd by Vander et al. (27) in studies on the dog. It is also known that the thiazide drugs act in the proximal renal tubule. Thus, one should expect the thiazides and spirolactones, bccause of thcir different sites of action, to potentiate one another. Such is the case, as will be discussed latcr, and this effiect supplies additional indirect evidence for the separate sites of action of these drugs.

\section{Other Pharmacological Effects}

Effects on adrenal function. The 17-spirolactone stcroids do not depress adrenal or pituitary function as measured by the 17-hydroxycorticosteroid concentration in the blood and urine, urinary 17-ketosteroids, and urinary aldosterone excretion $(10,22,28)$. The glucuronide-conjugated fraction of the 17-hydroxycorticosteroids in the urine has been reported to decrease during the administration of SC-8109. It should be pointed out that the administration of Aldactone interferes with the determination of 17-hydroxycorticosteroids by the Porter-Silber reaction, with the measurement of the 17-ketosteroids by the Zimmerman reaction, and with the chromatographic determination of aldosterone. When aldosterone secretion rates were determined by the isotope dilution technic in patients receiving Aldactone, the results were inconsistent $(20,29,30,31)$. The various findings probably reflect spontaneous day to day fluctuations in aldosterone excretion.

Measurements in patients with secondary aldosteronism have been more consistcnt. Under such circumstances a spirolactone administration is accompanied by an increased rate of aldosterone $(20,29,32,33)$.

Other endocrine effects. The 17-spirolactone steroids do not possess anti-inflammatory activitv. They are also without effect on carbohydrate metabolism. Conversely, they 
do not prevent the effect of cortisone on inflammatory reactions. Aldactone does not have estrogenic or androgenic activity and is not progestational in the experimental animal (14).

A positive nitrogen balance has been observed in patients with cirrhosis and ascites receiving SC-8109 (34). An increase in normal muscle mass in a patient with cirrhosis was also observed during treatment (35). Such an effect may represent an improved nutritional status following the production of diuresis. It may also indicate that excessive aldosterone activity in some way contributes to the study of protein depletion which is prevented when spirolactones are administered.

There are no indications that Aldactone changes serum protein-bound iodine levels.

Cardiovascular effects. SC-5233 will lower the blood pressure of hypertensive metacorticoid rats. SC-8109 and Aldactone are inactive in this test. SC-5233 also delays the development of hypertension in rats given DCA and saline and prevents the hypertension due to adrenal regeneration $(36,37)$. SC-8109 is inactive in these tests and Aldactone has not been evaluated by these procedures.

The spirolactones have been reported to potentiate the contraction of a strip of rabbit aorta immersed in epinephrine (38). Thus, in this effect the spirolactones resemble desoxycorticosterone in activity.

\section{GLINICAL EFFECTS}

The onset of activity of the spirolactones, including Aldactone, is slow. An increasing response occurs over the first three or four days of treatment, at which time a maximal effect is usually obtained. The duration of activity is approximately two to three days after administration of Aldactone is discontinued. Thus, these steroids differ significantly from the mercurials or thiazide diuretics which produce a dramatic diuresis on the first day of treatment, with diminishing effects as treatment is continued. In some patients employing the usual dose of 400 to $600 \mathrm{mg}$ of Aldactone per day, a week or more of treatment may be required to produce a significant reduction of edema. If on the other hand there is no increase of sodium excretion or weight loss after the administration of 800 to $1200 \mathrm{mg}$ of Aldactone for a week, it is probable that other diuretics will have to be used in addition to or in place of Aldactone. The metabolic fate of Aldactone is unknown.

Potentiation of diuretic effects of Aldactone. There is now abundant evidence demonstrating that many patients with edema who are refractory to thiazides or Aldactone may achieve a significant diuresis when these drugs are given in combination. The administration of Aldactone simultaneously with a mercurial or thiazide diuretic not only produces a synergistic effect on sodium and water excretion but also decreases or prevents the potassium loss associated with these diuretics.

A low sodium diet should always be used as such enhances the chance of producing a negative sodium balance and subsequent weight loss. If such patients do not respond to Aldactone alone or to combination therapy with other diuretics, a response may be 
obtatined by the further administration of a glucocorticoid. Morrison (41, 42) has observed that the administration of Aldactone in combination with a glucocorticoid and a mercurial or thiazide diuretic produces a diuresis in patients previously resistant to any of the agents given alone or in combination. Similar observations have been reported by Zimmerman and Gantt (44).

Cirrhosis of the liver. Patients with cirrhosis and edema and ascites almost without exception have large quantities of aldosterone in the urine. A number of authors have used Aldactone with success in the treatment of such patients $(29,39,33-35,40,41,43,45-$ 52). Aldactone employed alone in a daily dose range of 200 to $2400 \mathrm{mg}$ per day ordinarily produces a significant diuresis of sodium and water with accompanying weight decrease and clinically with improvement of about $40 \%$ in patients studied. The average dose required for patients in the United States has been in the neighborhood of about 400 to $600 \mathrm{mg}$ per day. In Japan the average dose required appears to be $200-400 \mathrm{mg}$ per day. Patients who do not respond to Aldactone may be treated with a combination of Aldactone and a thiazide or mercurial diuretic. Other patients may be resistant to a thiazide or mercurial drug. When such individuals are treated with a diuretic combination including Aldactone a large percent of such refractory patients responds to the combined treatment.

There is no evidence to indicate that spirolactone therapy increases blood ammonia concentration or induces hepatic coma $(34,35,41)$. In fact the reverse has been obscrved wherein the nervous complications in patients who had impending hepatic coma improved when spirolactone therapy was started (39). Potassium depletion as induced by mercurial or thiazide diurctics may precipitate hepatic coma (53). The ability of Aldactone to conserve potassium tends to counteract this effect.

Nephrotic syndrome. It has been demonstratcd that most patients with the nephrotic syndrome excrete large amounts aldosterone in the urine. The spirolactones increase urine, sodium, and water excretion with consequent weight loss and reduction or disappearance of the edema $(20,22,33)$. Mild degrees of azotemia and hypertension do not prevent a good diuresis from occurring treatment (20,33). As yet no reports have been published comparing the effectiveness of Aldactone therapy with glucocorticoid therapy in patients with nephrosis. It is also unknown whether remission can be reduced by Aldactone. It should be remembered that Aldactone does not possess an anti-inflammatory activity and will therefore not exhibit the known effect of corticosteroids in these patients. Since the anti-inflammatory effects of the corticosteroids appear to effect the basic pathological disorder of the basement membrane, Aldactone should not be used in place of the corticoid-treatment. However, in patients who do not respond to the glucocorticoid, Aldactone either alone or in combination with other diuretics appears to bc useful in promoting a diuresis.

Congestive heart failure. Several investigators have reported on the significance of aldosterone in the production and maintenance of edema in patients with congestive heart failure. In general it may be stated that patients with congestive heart failure 
have shown a more variable response to treatment with the spirolactones. Although somc patients have failed to respond, even when treatment has been prolonged, it has usually been observed that a statisfactory diuresis can be produced $(19,29,30,33,41)$. It is not known whether patients with different types of heart failure will differ in thcir response to Aldactone. There is, however, evidence to indicate that the spirolactones are useful alone or in combination in some patients who respond inadequately or who are resistant to treatment with other diuretics. Such patients may receive Aldactone together with a low sodium diet and chlorothiazide or a mercurial diuretic. The dose of Aldactone will depend on the response produced but it should be increased if necessary to 800 or $1200 \mathrm{mg}$ per day.

Essential hypertension. Both Genest el al. (54) and Laragh et al. (55) have reported incrcased excretion of aldosterone in patients with essential hypertension. A large individual variation does exist in the same patient from day to day. Hollander (56) has reported that $68 \%$ of his series of 32 paticnts showed a significant fall in blood pressure when treated with the spirolactone alone or with other agents. The reduction in blood pressure averaged $21 / 11 \mathrm{~mm} \mathrm{Hg}$ when Aldactone was used alone. When Aldactone was used with other drugs, the fall in blood pressure ranged from $15 / 10$ to $55 / 30 \mathrm{~mm} \mathrm{Hg}$. Similar results have been obtained by Genest $(20,57)$. In contrast, patients with renal hypertension seldom experience a fall in blood prcssure.

It is known that potent diurctics, such as chlorothiazide and the mercurials, will lower blood pressure when given alone and will potentiate the effects of conventional antihypertensive therapy. Patients with essential hypertension who have shown some response to chlorothiazide obtain a further diuresis of sodium and decrease in blood pressure when a spirolactone is added to therapy. Further studies will be required to further delineate the exact usefulness of such combined therapy. If aldosterone plays an etiolgical rolc in the development of hypertension, such therapy may be important. Combined therapy with Aldactone and chlorothiazide, given for two months, prevented the potassium depletion that occurred when chlorothiazide was given alone.

Primary hyperaldosteronism. The syndrome of hyperaldosteronism, duc cither to adrenal tumor or adrenal hyperplasia was first described by Conn and Louis (58). The hypokalemia and alkalosis of primary aldosteronism are readily reversed by the spirolactones (59-61). The doses of Aldactone required to produce significant effects in such patients arc usually much greater than the doses acquired to achieve diuresis in patients with edema. Since most patients have one or more adrenal cortical adenomas, it is unlikely that the use of Aldactone will replace adrenalectomy as the treatment of choice. However, treatment with Aldactone in doses of 800 to $1000 \mathrm{mg}$ for several weeks will serve to improve the general condition of the patient prior to surgery. Aldactone may also be of value in the diagnosis of primary aldostcronism and to differentiate from such condition as "potassium-losing nephritis" in which the hypokalemia will presumably be uneffected.

Idiopathic edema. Certain patients with idiopathic edema respond poorly to Aldactone 
administration whereas othcrs achieve a satisfactory diuresis $(62,63)$. When resistance to chlorothiazide occurs, combincd treatment with Aldactone has been continuously effective in some patients for many months.

Toxemia of pregnancy. Recent evident indicates that aldosterone is not an important etiologic factor in toxemia in pregnancy. Although the output of aldosterone in such patients was higher than in the nonpregnant subject it was usually lower than in pregnant women who had no signs of toxemia $(61,65,66)$. It is not surprising therefore that SC8109 did not produce a diuresis in the toxic patient (64). Normal pregnant patients (without toxemia) respond to the spirolactones with a diuresis of sodium and water.

Side effects of treatment. Aldactone has been relatively free of side effects. Five paticnts have becn reported who developed pruritic drug rash while receiving the compound. These cutaneous reactions were not serious and subsided rapidly when the drug was discontinued. Streeton (17) has noted one patient, receiving $1.2 \mathrm{~g}$ of Aldactone per day, with tenderness of the breasts. He also observed mild hirsutism in another after several months of treatment with $500 \mathrm{mg}$ of Aldactone daily.

The only other reactions have consisted of manifestations which may accompany excessive degree of aldosterone antagonism, such as hyperkalemia, hyponatremia, dizziness, and postural hypotension. Hyperkalemia is more likely to occur when potassium supplements are being administered during treatment. The tendency towards hyponatremia and postural hypotension may be due to excessively reduced sodium intake or excessive sodium cxcretion. Hyponatremia probably also results from failure of the rate of water excretion to occur at the same rate as the urinary loss of sodium. It may be overcome by reducing the dose of the drug or by administering a glucocorticoid.

\section{SUMMARY}

The spirolactones are drugs which exert an aldostcrone-blocking effect. Aldosterone plays a significant role in the development of edema in certain disease states and the administration of spironolactone (Aldactone) to such patients will produce a diuresis. Because of its aldosterone-blccking effects Aldactone is of particular value in the patient who has become refractory to continued treatment with the thiazides or mercurials. In contrast to the thiazides and mercurials, Aldactone appears to retain its effect in promoting sodium excretion for many months or even years when used alone or in combination with other diuretics. The acute diuretic potency of Aldactone is not comparable to that of the thiazides or mercurial diuretics. However, as Morrison has pointed out there is something to be gained from a drug that will produce a slow but progressive diuresis over a period of several weeks than from an agent that acts more rapidly but looses its effectiveness when used daily.

Secondly, Aldactone neither increases urinary potassium increase nor decreases serum concentration as most other diuretics do. In fact, Aldactone will reverse the tendency of the thiazide drugs to produce potassium depletion.

Lastly, since aldosterone acts in the distal renal tubules to causc sodium retention 
and potassium excretion, Aldactone also exerts its blocking effect at the distal tubules. Such is in contrast to the mercurials and thiazides which produce their effect in the proximal tubules of the kidney. Thus, because of the different sites of action of these compounds Aldactone in combination with the other diuretics can produce a true synergistic diuretic effect, which is very valuable in the patient with resistent edema.

\section{REFERENCES}

1) Deming, Q.B. And Luetscher, J.A. : Proc. Soc. exper. Biol., N.Y. 73, 171 (1950)

2) Gaunt, R., Renzl, A.A. ANd Chart, J.J. : J. clin. Endocr. 15, 621 (1955)

3) BArTter, F.C. : Metabolism 5, 369 (1956)

4) Laragil, J.H. : Amer. J. Med. 21, 423 (1956)

5) Simpson, S.A., TAIT, J.F. And Bush, I.E. : Lancet 2, 226 (1952)

6) Luetscher, J.A., JR., Neher, R. And Wettstein, A. : Experientia 10, 456 (1954)

7) Luerscier, J.A., JR., Neher, R. AND Wettstein, A. : Ibid. 12, 22 (1956)

8) Kagawa, C.M., Cella, J.A. and Van ARman, C.G. : Science 126, 1015 (1957)

9) Cella, J.A. And Kagawa, C.M. : J. Amer. Chem. Soc. 79, 4808 (1957)

10) LiDnLe, G.W. : Science 126, 1016 (1957)

11) Kagawa, C.M., Sturtevant, F.M. and Van Arman, C.G. : J. Pharmacol. 126, 123 (1959)

12) KaGaWA, C.M. : Endocrinology 67, 125 (1960)

13) Kagawa, C.M. : Univ. of Michigan Med. Bull. 26, 251 (1960)

14) Kagawa, C.M. : Hahnemann Symposium on Edema : Mechanism and Management. Ed. by MoYtr, J.H. and Fuchs, M. p. 309. W.B. Saunders Co., Priladelphia (1960)

15) Bartter, F.C., editor : The Clinical Use of Aldosterone Antagonists. Gharles G. Thomas, Springfield, Ill. (1960)

16) GaNTT, C.L. : N.Y. State J. of Med. 61, 756 (1961)

17) Streeten, D.H.P. : Clin. Pharmacol. and Therap. 2, 359 (1961)

18) Wiggins, R.A., Hutchin, M.E., Garbone, J.V. and Doolan, P.D. : Proc. Soc. exper. Biol., N.Y. 100, 625 (1959)

19) Cejka, V., De Votes, L.A. and Borst, J.G.G. : Lancet 1, 312 (1960)

20) Genest, J. : BartTer, F.C. (15)

21) Conn, J.W., et al. : J. Lab. clin. Med. 52, 805 (1958)

22) LinnL., G.W. : Arch. Intern. Med. 102, 998 (1958)

23) Bartter, C.F. : Ref. BartTer, G.F. (15)

24) Ross, E.J. and Bethune, J.E. : Lancet 1, 127 (1959)

25) Liddle, G.W. : Ref. BarTter, C.F. (I5)

26) Salassa, R.M., Mattox, V.R. and Power, M.H. : J. clin. Endocr. 18, 787 (1958)

27) VAnder, A.J., et al. : Proc. Soc. exper. Biol., N.Y. 99, 323 (1958)

28) Gantt, C.L. And Dyniewicz, J. : Clin. Res. 7, 294 (1959)

29) Bor.TF, E., et al. : Canad. med. Ass. J. 79, 881 (1958)

30) LARAGH, J. : Ref. BAR'TTER, C.F. (15)

31) FEterson, R.E. : Ref. BARTter, C.F. (15)

32) Ricitard, J. : Ref. BartTFr, C.F. (15)

33) Stater, J. D. H., Mokham, A., Hurter, R. and Nabarro, J.D.N. : Lancet 2, 931 (1959)

34) FaLoon, W.W. : Ref, Barttir, C.F. (15) 
35) GantT, C.L. : Ref. BartTer, C.F. (15)

36) Sturtevant, F.M. : Science 127, 1393 (1958)

37) Sturtevant, F.M. : Endocrinology 64, 299 (1959)

38) Bohr, D.F. and Oummings, G. : Fed. Proc. 17, 17 (1958)

39) Clowdus, B.F., et al. : Proc. Mayo Clin. 35, 97 (1960)

40) Henley, K.S., Streeten, D.H.P. and Pollard, H.M. : Gastroenterology 38, 681 (1960)

41) Morrison, R.S. : Ref. BARTter, C.F. (15)

42) Morrison, R.S. and Ghalmers, T.G. : Clin. Res. 7, 37 (1959)

43) Shaldon, S., Mclaren, J.R. and Sherlock, S. : Lancet 1, 609 (1960)

44) Zimmerman, H.J. and GantT, G.L. : Ref. MOYer, J.H. And FuChs, M. (14)

45) Friedberg, C.K. : Ref. Bartter, F.G. (15)

46) Morrison, R.S. and Chalmers, T. C. : Clin. Res. 6, 300 (1958)

47) Steisenger, M.H. : Ref. Bartter, C.F. (15)

48) Manning, R.T. : Ref. BartTer, C.F. (15)

49) Kowi.gssar, O.D., Glarkson, B. and Sleisenger, M.H. : Clin. Res. 7, 37 (1959)

50) TAylor, F.F. ANd FaloOn, W.W. : J. clin. Endocr, 19, 1683 (1959)

51) Hellman, S. and Faloon, W.W. : J. Lab. clin. Med. 55, 872 (1960)

52) Henley, K.S. : Ref. Bartter, C.F. (15)

53) Sherlock, S., et at. : Ann. N. Y. Acad. Sci. 71, 430 (1959)

54) Genest, J., et al. : Clin. Res. 6, 28 (1958)

55) LaraGH, J.H., et al. : J. clin. Invest. 39, 1091 (1960)

56) Hollander, W. : Ref. BartTer, G.F. (15)

57) Genest, J., et al. : Proc. Soc. exper. Biol., N.Y. 97, 676 (1958)

58) Conn, J.W. And Louis, L.H. : Ann. Intern. Med. 44, 1 (1956)

59) Salassa, R.M., Mattox, V.R. and Power, M.H. : J. clin. Endocr. 18, 787 (1958)

60) Kistler, H., Shfli.ey, T.F. and Frawley, T.F. : Clin. Res. 7, 254 (1959)

61) Kogzorek, K.R., WolfF, H.P. And Beer, M.L. : Klin. Wschr. 35, 497 (1957)

62) Streeten, D.H.P. : Ref. BartTer, C.F. (15)

63) Streeten, D.H.P., Louis, L.H. And Conn, J.W. : Tr. A. Am. Physicians 73, 227 (1960)

64) Barnes, A.C. And Buckingham, J.C. : Amer. J. Obstet. Gynec. 76, 955 (1958)

65) Kumar, D., Feitham, L.A.W. And Gornall, A.G. : Lancet 1, 541 (1959)

66) VenNing, E.H., et al. : J. clin. Endocr. 17, 473 (1957) 